\title{
Perdiz arrow points from Caddo burial contexts aid in defining discrete behavioral regions
}

\author{
Robert Z. Selden 1 • John E. Dockall 2 •
}

Received: date / Accepted: date

\begin{abstract}
Recent research into Caddo bottle and biface morphology yielded evidence for two distinct behavioral regions, across which material culture from Caddo burials expresses significant morphological differences. This study asks whether Perdiz arrow points from Caddo burials differ across the same geography, which would extend the pattern of morphological differences to a third category of Caddo material culture. Perdiz arrow points collected from the geographies of the northern and southern Caddo behavioral regions were employed to test the hypothesis that morphological attributes differ, and are predictable, between the two communities. The analysis of linear metrics indicated a significant difference in morphology by behavioral region. Using the linear metrics combined with the tools of machine learning, a predictive modelsupport vector machine - was designed to assess the degree to which community differences could be predicted, achieving a receiver operator curve score of 97 percent, and an accuracy score of 94 percent. The subsequent landmark geometric morphometric analysis identified significant differences in Perdiz arrow point shape and size between the behavioral regions - one characterized
\end{abstract}

Components of the analytical workflow were developed and funded by a Preservation Technology and Training grant (P14AP00138) to RZS from the National Center for Preservation Technology and Training, as well as grants to RZS from the Caddo Nation of Oklahoma, National Forests and Grasslands in Texas (15-PA-11081300-033) and the United States Forest Service (20-PA-11081300-074). Additional financial and logistical support was provided by the Heritage Research Center at Stephen F. Austin State University.

Robert Z. Selden 1

Heritage Research Center, Stephen F. Austin State University; Department of Biology, Stephen F. Austin State University; Texas Archeological Research Laboratory, The University of Texas at Austin; and Cultural Heritage Department, Jean Monnet University E-mail: zselden@sfasu.edu

John E. Dockall 2

Stantec, Inc.

E-mail: john.dockall@stantec.com 
by a comparatively smaller blade and larger stem (north), and the other by a comparatively larger blade and smaller stem (south) - coupled with significant results for modularity and morphological integration. These findings build directly upon recent investigations that posited two discrete Caddo behavioral regions defined on the basis of discernible morphological differences, which is expanded here to include a third category of Caddo material culture.

Keywords American Southeast · Caddo - NAGPRA · computational archaeology $\cdot$ archaeoinformatics $\cdot$ machine learning $\cdot$ museum studies $\cdot$ digital humanities $\cdot$ non-Western art history $\cdot$ STEM $\cdot$ STEAM ·

\section{Introduction}

Perdiz arrow points are considered the epitome of the Late Prehistoric Toyah lithic assemblage in Texas - which also includes convex end scrapers or unifaces, prismatic blades, as well as two- and four-beveled bifacial knives - and are representative of the Late Prehistoric transition to the Protohistoric [10. This technological assemblage is typically attributed to groups of highly mobile bison hunters, and has been documented across the geographic extent of Texas. Our present understanding of the Toyah tool kit indicates that it was successfully implemented in a broad-spectrum of hunting and foraging lifeways that included not only bison (Bison bison), but deer (Odocoileus spp.) and numerous other animal prey species [10,25].

The Toyah tool kit has been recognized as a potential contributor to discussions of Late Prehistoric social and cultural identity. Initially identified by J. Charles Kelley on the basis of technological and morphological differences in material culture, the Toyah Phase (CE 1300 - 1700) occurrs between the Protohistoric and the preceding Austin Phase of the Late Prehistoric Period [38, 39. As noted by Arnn:

Toyah represents something of a paradox in which archaeologists have identified one archaeological or material culture in the same region where historians have documented numerous Native American groups and significant cultural diversity [10, 47].

Stemming from the observations of Kelley, as well as later researchers who viewed Toyah as a cultural entity, technological origins became a point of further interest and debate from which two schools of thought emerged regarding Toyah cultural manifestations: 1) that Toyah represented the technology of Plains groups moving into Texas following the bison herds [54,55, or 2) a technocomplex or suite of artifacts adopted by multiple groups across Texas as they participated in bison hunting [16,21, 58. In both interpretations, primary agency is environmental [10; either people followed the bison from elsewhere, or the influx of bison spurred adoption of the technology among the numerous groups in Texas. 
Research by Arnn [10,8,9,11, emphasized aspects of Toyah social identity, social fields, and agency, as well as the archaeological visibility of these phenomena. Arnn recognized three important scales of identity and interaction in his work: community/band, marriage/linguistic group, and long-distance social networks 10. His ideas are important here because they supplant a simple monocausal environmental explanation of material culture variability with a multi-causal and scaled concept that includes social identity.

\subsection{Perdiz arrow points}

Perdiz arrow points generally follow two manufacturing trajectories - one that enlists flakes, and the other, blade flakes 26, 35, 57, 67 — and are known to encompass a greater range of variation in shape and size than most arrow point types in Texas [75, 78. Lithic tool stone in the ancestral Caddo area of northeast Texas is relatively sparse [67, Figure 2], consists primarily of chert, quartzite, and silicified wood characteristic of the local geological formations, which may contribute to local variation in shape and size 67,13. It has been demonstrated elsewhere that the morphological attributes of Perdiz arrow points from northeast Texas vary significantly by time, raw material, and burial context [67. In outline, Perdiz arrow points possess a:

[t]riangular blade with edges usually quite straight but sometimes slightly convex or concave. Shoulders sometimes at right angles to stem but usually well barbed. Stem contracted, often quite sharp at base, but may be somewhat rounded. Occasionally, specimen may be worked on one face only or mainly on one face ... [w]orkmanship generally good, sometimes exceedingly fine with minutely serrated blade edges [76, 504].

A social network analysis of diagnostic artifacts from Historic Caddo (postCE 1680) sites in northeast Texas, which included Perdiz arrow points, demonstrated two spatially discrete behavioral regions based upon the co-presence of diagnostic types [65, Figure 12.4]. The network analysis was limited to Historic Caddo types; however, Formative/Early Caddo (CE 800 - 1200) Gahagan bifaces and Caddo bottle types have been found to express significant morphological differences across the same spatial extent as the behavioral regions 62, 63, 64, 66], extending the prehistoric longevity for the behavioral regions based on local alterity. Gahagan bifaces from the ancestral Caddo area also differ significantly in shape, size, and form compared with those recovered from central Texas sites 68, suggesting a second shape boundary between the ancestral Caddo area and central Texas.

The goal of this exploratory endeavor was to assess whether metrics collected for Perdiz arrow points support the shape boundary posited in recent social network and geometric morphometric analyses, to determine whether linear metrics and shape variables might be useful predictors of regional membership, and - if so - to identify those morphological features that articulate with each behavioral region. Should the analysis yield significant results, it 


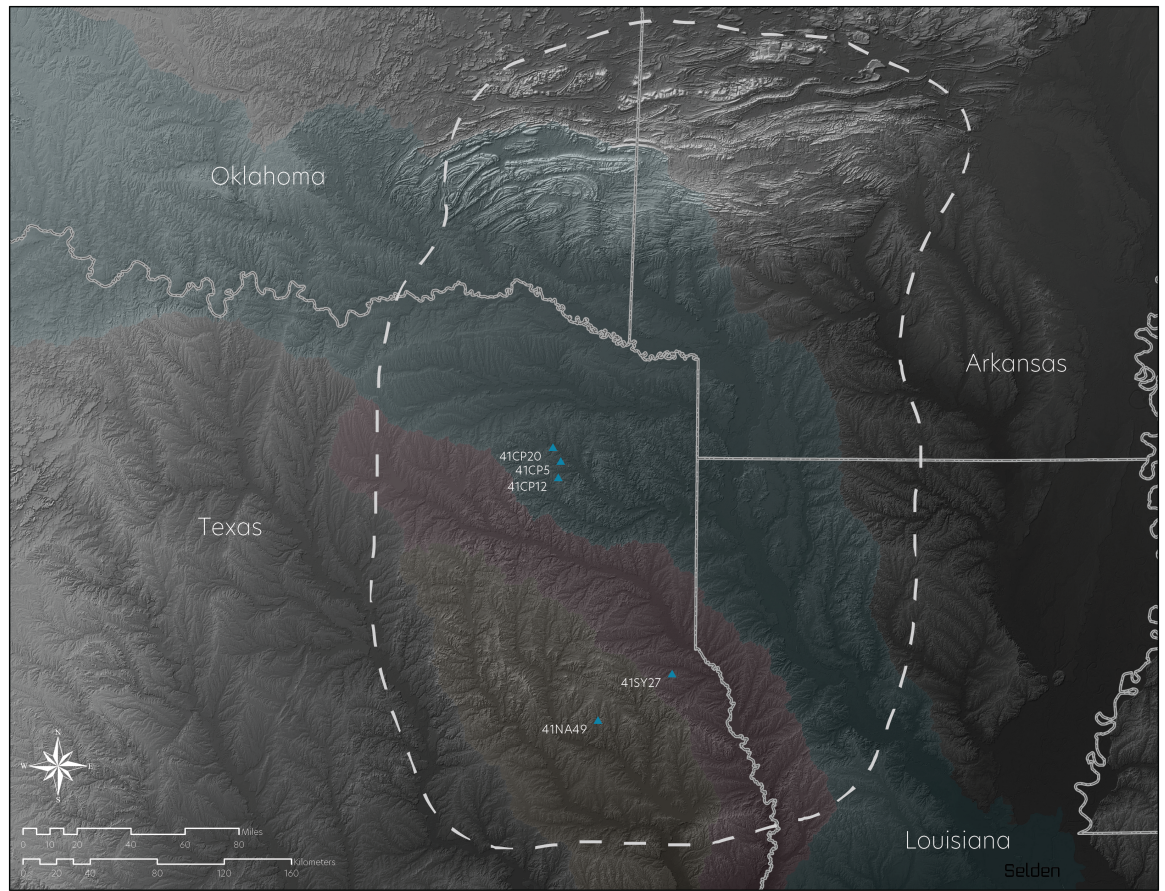

Fig. 1 Location of Caddo sites with Perdiz arrow points used in this study, the extent of the ancestral Caddo area (white), and the Red River basin (blue), Sabine River basin (maroon), and Angelina River basin (brown).

would bolster the argument for at least two discrete Caddo behavioral regions in northeast Texas; each empirically defined by discernible morphological differences across three discrete categories of Caddo material culture (Figure 1).

\subsection{Caddo behavioral regions}

In a June 18, 1937 Works Progress Administration interview with Lillian Cassaway, Sadie Bedoka - a Caddo-Delaware woman raised with the Caddo - stated that:

Each [Caddo] clan had its own shape to make its pottery. One clan never thought of making anything the same pattern of another clan.

You could tell who made the pottery by the shape [20, 395].

General differences in Caddo ceramic forms have been noted elsewhere 44 70]; however, the study of the Clarence $\mathrm{H}$. Webb collection was the first to illustrate a significant north-south geographic shape difference among Hickory Engraved and Smithport Plain Caddo bottle types 64. That exploratory aperçu was later confirmed using more robust samples of Hickory Engraved and Smithport Plain bottles [62,63, and was subsequently expanded to include 
a greater variety of Caddo bottle types across a larger spatial and temporal extent [66.

The co-presence of diagnostic artifact and attribute types was leveraged in defining Caddo phases and periods, which serve as a heuristic tool that aids archaeologists in the explanation and retrojection of the local cultural landscape, whilst simultaneously highlighting the regional alterity that occurs between landscapes. The Historic Caddo network expands those efforts, augmenting the previously-defined phases and periods, and emphasizing the dynamic and manifold relational connections that reinforce and transcend current epistemic categories [65. This was achieved by enlisting a multi-scalar methodological approach 43, 48, where northern and southern communities were parsed into constituent groups using the co-presence of diagnostic types paired with a modularity algorithm [17,45]. Most constituent groups identified in the network analysis were found to articulate with known Caddo polities [65.

A subsequent analysis of Gahagan bifaces confirmed that a second category of Caddo material culture expressed significant morphological differences across the same geography as the Hickory Engraved and Smithport Plain bottles 69. The morphology of Gahagan bifaces from sites in central Texas has also been found to differ significantly from those recovered from the Caddo region 68. That Gahagan bifaces were found to differ across two spatial boundaries was noteworthy, particularly since it is regularly assumed that these large bifaces were manufactured in central Texas and arrived in the ancestral Caddo area as products of trade and/or exchange [68,69]. Further, that Gahagan bifaces were found to differ across the same geography as those communities posited in the Historic Caddo network analysis suggested that the temporal range of the shape boundary might extend to the Formative/Early Caddo period (CE 800 - 1250); a hypothesis that was later confirmed in a more comprehensive analysis of Caddo bottles [6].

\section{Methods and results}

Sixty seven whole/intact Perdiz arrow points recovered from Caddo burial contexts in Camp, Nacogdoches, and Shelby counties comprise the basis of this study (supplementary materials). A standard suite of linear metrics were collected for each specimen, including maximum length, width, thickness, stem length, and stem width (Table @ref\{tab:table1\}). Following collection, data were imported to $\mathrm{R}$ [77, where boxplots were produced, along with a principal components analysis (PCA), followed by a permutational multivariate analysis of variance (perMANOVA) to test whether the morphology of Perdiz arrow points differs between the behavioral regions (supplementary materials). 
Table 1: Sample overview: Linear metrics and categorical variables used in the study, which include maximum length (MaxL), width (MaxW), thickness (MaxTh), stem length (MaxStL), and stem width (MaxStW).

\begin{tabular}{|c|c|c|c|c|c|c|c|}
\hline ID & Site & Region & MaxL & MaxW & MaxTh & MaxStl & MaxStw \\
\hline 554 & 41cp12 & north & 25.40 & 12.18 & 3.82 & 5.75 & 3.84 \\
\hline 555 & 41cp12 & north & 22.92 & 12.87 & 3.54 & 3.71 & 3.69 \\
\hline 556 & 41cp12 & north & 24.09 & 11.87 & 3.61 & 5.15 & 4.78 \\
\hline 559 & 41cp12 & north & 25.01 & 10.57 & 3.50 & 5.84 & 3.88 \\
\hline 562 & 41cp12 & north & 22.10 & 10.45 & 3.47 & 3.77 & 3.43 \\
\hline 565 & 41cp12 & north & 20.31 & 10.53 & 3.08 & 2.01 & 3.07 \\
\hline 591 & $41 \mathrm{cp} 12$ & north & 25.49 & 13.37 & 4.42 & 7.04 & 4.95 \\
\hline 646 & 41cp5 & north & 16.37 & 10.46 & 2.63 & 3.85 & 4.03 \\
\hline 649 & $41 \mathrm{cp} 5$ & north & 23.38 & 13.88 & 4.11 & 7.33 & 5.54 \\
\hline 651 & $41 \mathrm{cp} 5$ & north & 22.86 & 13.84 & 4.61 & 6.16 & 5.02 \\
\hline 652 & $41 \mathrm{cp} 5$ & north & 22.51 & 12.67 & 3.37 & 6.33 & 4.39 \\
\hline 653 & $41 \mathrm{cp} 5$ & north & 27.55 & 17.05 & 3.08 & 6.83 & 4.60 \\
\hline 654 & $41 \mathrm{cp} 5$ & north & 17.01 & 10.90 & 2.35 & 4.64 & 3.64 \\
\hline 655 & $41 \mathrm{cp} 5$ & north & 26.86 & 13.06 & 2.50 & 6.10 & 3.99 \\
\hline 656 & $41 \mathrm{cp} 5$ & north & 25.79 & 12.52 & 2.96 & 5.43 & 3.97 \\
\hline 657 & $41 \mathrm{cp} 5$ & north & 27.36 & 12.41 & 3.04 & 6.56 & 4.26 \\
\hline 659 & $41 \mathrm{cp} 5$ & north & 23.10 & 11.42 & 2.14 & 4.74 & 4.21 \\
\hline 660 & $41 \mathrm{cp} 5$ & north & 20.23 & 9.64 & 1.89 & 5.70 & 2.66 \\
\hline 661 & 41cp5 & north & 21.73 & 10.67 & 2.27 & 4.91 & 3.13 \\
\hline 665 & $41 \mathrm{cp} 12$ & north & 27.34 & 15.77 & 4.10 & 4.69 & 4.60 \\
\hline 677 & $41 \mathrm{cp} 20$ & north & 24.72 & 13.70 & 2.52 & 6.98 & 3.76 \\
\hline 678 & $41 c p 20$ & north & 24.98 & 13.33 & 3.26 & 4.19 & 3.54 \\
\hline na49-1 & 41na49 & south & 47.74 & 15.14 & 4.52 & 6.82 & 6.22 \\
\hline na49-10 & 41na49 & south & 22.88 & 12.13 & 3.68 & 5.73 & 5.49 \\
\hline na49-11 & 41na49 & south & 24.09 & 12.52 & 3.27 & 5.36 & 4.81 \\
\hline na49-12 & 41na49 & south & 21.41 & 10.31 & 3.48 & 4.64 & 3.82 \\
\hline na49-13 & 41na49 & south & 24.84 & 11.21 & 3.51 & 5.19 & 4.97 \\
\hline na49-14 & 41na49 & south & 21.92 & 9.35 & 2.62 & 5.22 & 4.85 \\
\hline na49-2 & 41na49 & south & 32.49 & 12.78 & 3.80 & 6.80 & 4.78 \\
\hline na49-3 & 41na49 & south & 27.72 & 13.05 & 4.19 & 5.99 & 5.88 \\
\hline na49-4 & 41 na49 & south & 26.20 & 10.60 & 3.30 & 4.67 & 4.92 \\
\hline na49-7 & 41na49 & south & 24.25 & 12.01 & 2.92 & 6.01 & 4.93 \\
\hline na49-8 & 41na49 & south & 22.06 & 14.51 & 2.92 & 5.67 & 5.17 \\
\hline na49-9 & 41na49 & south & 25.44 & 13.86 & 3.44 & 4.74 & 4.81 \\
\hline f2-g2-5 & 41 sy 27 & south & 24.92 & 16.16 & 3.57 & 4.44 & 4.25 \\
\hline f2-g2-10 & 41 sy 27 & south & 34.69 & 16.40 & 3.29 & 6.12 & 4.14 \\
\hline f2-g2-15 & 41 sy 27 & south & 34.17 & 20.00 & 3.09 & 8.34 & 5.68 \\
\hline f2-g2-9 & 41 sy 27 & south & 39.39 & 16.73 & 2.95 & 6.28 & 4.90 \\
\hline f2-g2-14 & 41sy 27 & south & 30.36 & 15.72 & 2.58 & 6.11 & 4.51 \\
\hline
\end{tabular}




\begin{tabular}{|c|c|c|c|c|c|c|c|}
\hline ID & Site & Region & MaxL & MaxW & MaxTh & MaxStl & MaxStw \\
\hline $\mathrm{f} 2-\mathrm{g} 2-2$ & 41sy 27 & south & 29.32 & 15.47 & 2.94 & 5.59 & 4.18 \\
\hline f2-g2-1 & 41sy 27 & south & 30.83 & 16.80 & 2.96 & 5.83 & 5.21 \\
\hline f2-g2-11 & 41sy 27 & south & 31.10 & 15.33 & 2.92 & 5.60 & 4.78 \\
\hline f2-g2-3 & 41sy 27 & south & 23.30 & 15.31 & 3.09 & 3.87 & 4.31 \\
\hline f2-g2-13 & 41sy27 & south & 29.33 & 18.59 & 3.13 & 5.54 & 4.52 \\
\hline f2-g2-7 & 41sy 27 & south & 24.78 & 15.68 & 3.20 & 4.60 & 4.23 \\
\hline f2-g2-8 & 41sy 27 & south & 28.17 & 18.24 & 3.01 & 5.99 & 4.72 \\
\hline f2-g2-12 & 41sy 27 & south & 33.53 & 15.83 & 3.18 & 5.55 & 4.23 \\
\hline f2-g2-6 & 41sy 27 & south & 23.74 & 16.12 & 2.92 & 5.53 & 4.34 \\
\hline f2-g1-20 & 41 sy 27 & south & 37.46 & 16.78 & 3.28 & 7.53 & 5.54 \\
\hline f2-g $1-10$ & 41sy 27 & south & 27.32 & 18.39 & 3.10 & 5.37 & 4.54 \\
\hline f2-g1-19 & 41 sy 27 & south & 31.44 & 19.62 & 3.13 & 5.44 & 5.75 \\
\hline f2-g1-17 & 41sy 27 & south & 32.75 & 19.34 & 3.34 & 6.29 & 5.31 \\
\hline f2-g1-16 & 41 sy 27 & south & 34.97 & 16.81 & 3.39 & 5.90 & 5.49 \\
\hline f2-g1-11 & 41sy 27 & south & 33.18 & 17.45 & 3.36 & 6.47 & 5.12 \\
\hline f2-g1-13 & 41sy 27 & south & 31.61 & 18.57 & 3.07 & 5.75 & 5.04 \\
\hline f2-g1-15 & 41sy 27 & south & 38.50 & 20.34 & 3.40 & 8.85 & 6.16 \\
\hline f2-g1-18 & 41sy 27 & south & 30.02 & 17.33 & 3.21 & 7.05 & 5.18 \\
\hline f2-g1-3 & 41sy 27 & south & 29.45 & 18.84 & 3.16 & 5.58 & 5.32 \\
\hline f2-g1-7 & 41sy 27 & south & 32.44 & 18.20 & 3.28 & 5.80 & 4.76 \\
\hline f2-g1-4 & 41sy 27 & south & 28.33 & 17.49 & 2.98 & 7.29 & 4.83 \\
\hline f2-g1-12 & 41 sy 27 & south & 32.17 & 18.47 & 3.47 & 5.44 & 5.20 \\
\hline f2-g1-8 & 41sy 27 & south & 31.03 & 17.05 & 3.10 & 7.41 & 5.11 \\
\hline f2-g1-9 & 41 sy 27 & south & 27.56 & 21.12 & 3.47 & 6.84 & 5.07 \\
\hline f2-g3-1 & 41sy 27 & south & 27.21 & 17.41 & 3.52 & 7.70 & 5.35 \\
\hline f2-g3-3 & 41 sy 27 & south & 24.31 & 16.35 & 3.00 & 7.08 & 5.10 \\
\hline f2-g3-6 & 41 sy 27 & south & 30.58 & 18.03 & 3.56 & 7.37 & 4.81 \\
\hline f2-g3-2 & 41 sy 27 & south & 27.63 & 17.74 & 2.99 & 8.23 & 4.82 \\
\hline
\end{tabular}

Boxplots illustrate the distribution and mean for each of the five linear variables (Figure 2a-e), and the PCA (Figure 2;) illustrates over 92 percent of the variation in the sample among PC1 (84.65 percent) and PC2 (11.71 percent). The perMANOVA demonstrated that linear metrics for Perdiz arrow points differ significantly by behavioral region (permutations $=10,000 ;$ Rsq $=$ $0.29485 ; \operatorname{Pr}(>\mathrm{F})=1 \mathrm{e}-04)$ (supplementary materials).

\subsection{Predictive model}

A support vector machine is a supervised machine learning model regularly used in classifying archaeological materials [14, 49,29, 37, 80, 28, which has utility in comparing and classifying datasets aggregated from digital repositories, comparative collections, open access reports, as well as other digital assets. For this effort, linear data were imported and modeled using the scikit-learn 

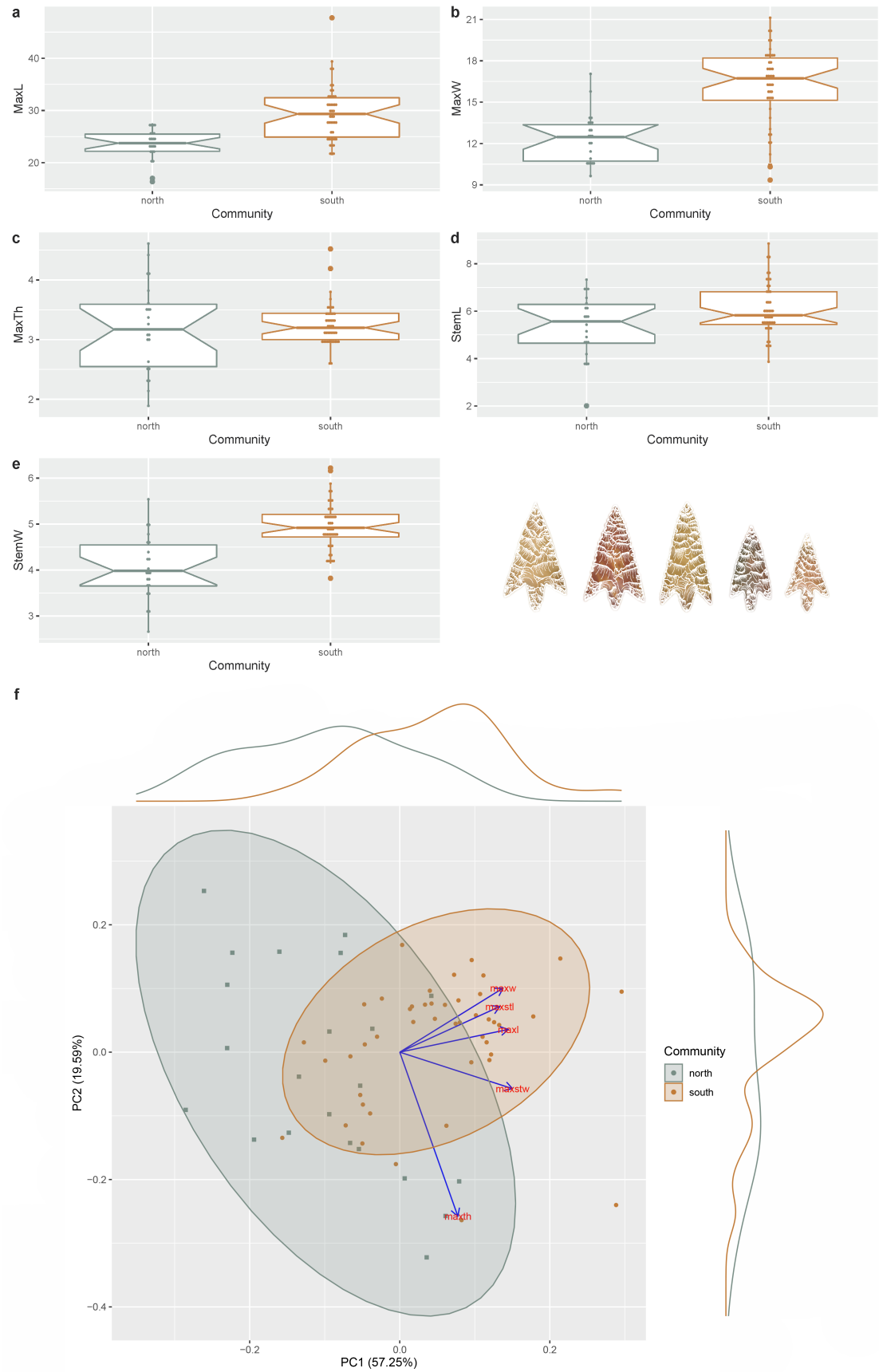

Fig. 2 Boxplots for a, maximum length; b, maximum width; c, maximum thickness; d, stem length; e, stem width, and f, PCA [on correlation matrix] for linear metrics associated with the Perdiz arrow points. Additional information related to the analysis, including all linear data and the code needed to reproduce these results, can be found in the supplemental materials at https://seldenlab.github.io/perdiz3/. 
package in Python [51,19] (supplementary materials), and subsequently split into training (75 percent) and testing (25 percent) subsets. A standard scaler was used to decrease the sensitivity of the algorithm to outliers by standardizing features, and a nested cross validation of the training set was used to achieve unbiased estimates of model performance, resulting in a mean cross validation score of 86 percent (supplementary materials). The model was subsequently fit on the training set, yielding a receiver operator curve score of 97 percent, and an accuracy score of 94 percent (supplementary materials).

\subsection{Geometric morphometrics}

Each of the arrow points was imaged using a flatbed scanner (HP Scanjet G4050) at 600 dpi. The landmarking protocol developed for this study (supplementary materials) included six landmarks and 24 equidistant semilandmarks to characterize Perdiz arrow point shape, and were applied using the StereoMorph package in $\mathrm{R}$ [50]. The characteristic points and tangents used in the landmarking protocol were inspired by the work of Birkhoff [15].

Landmarks were aligned to a global coordinate system [40,41,73], achieved through generalized Procrustes superimposition 60, performed in R 4.1.1 [77] using the geomorph package v4.0.1 [5, 12] (Figure 3). Procrustes superimposition translates, scales, and rotates the coordinate data allowing for comparisons among objects 32,60 . The geomorph package uses a partial Procrustes superimposition that projects the aligned specimens into tangent space subsequent to alignment in preparation for the use of multivariate methods that assume linear space [59,73.

Principal components analysis [36, 56] was used to visualize shape variation among the arrow points (Figure 4). Shape changes described by each principal axis are commonly visualized using thin-plate spline warping of a reference image or 3D mesh [42,72]. A residual randomization permutation procedure (RRPP; $\mathrm{n}=10,000$ permutations) was used for all Procrustes ANOVAs [1, 22 , which has higher statistical power and a greater ability to identify patterns in the data should they be present [7. To assess whether shape differs by group (region), Procrustes ANOVAs [31] were also run that enlist effect-sizes (z-scores) computed as standard deviates of the generated sampling distributions [23]. Procrustes variance was used to discriminate between regions and compare the amount of shape variation (morphological disparity) [79], estimated as Procrustes variance using residuals of linear model fit [4. A pairwise comparison of morphological integration was used to test the strength of integration between blade and basal morphology using a z-score [18, 23, 2, 3 .

A Procrustes ANOVA was used to test for a difference in Perdiz arrow point (centroid) size by behavioral region $(\mathrm{RRPP}=10,000 ; \mathrm{Rsq}=0.30681$; $\operatorname{Pr}(>\mathrm{F})=1 \mathrm{e}-04)$, followed by a second to test for a difference in arrow point shape $(\mathrm{RRPP}=10,000 ; \mathrm{Rsq}=0.0536 ; \operatorname{Pr}(>\mathrm{F})=0.0161)$. While shape and size differ significantly between behavioral regions, the Rsq value for size is just under six times larger than that for shape (smaller in the north; larger in 

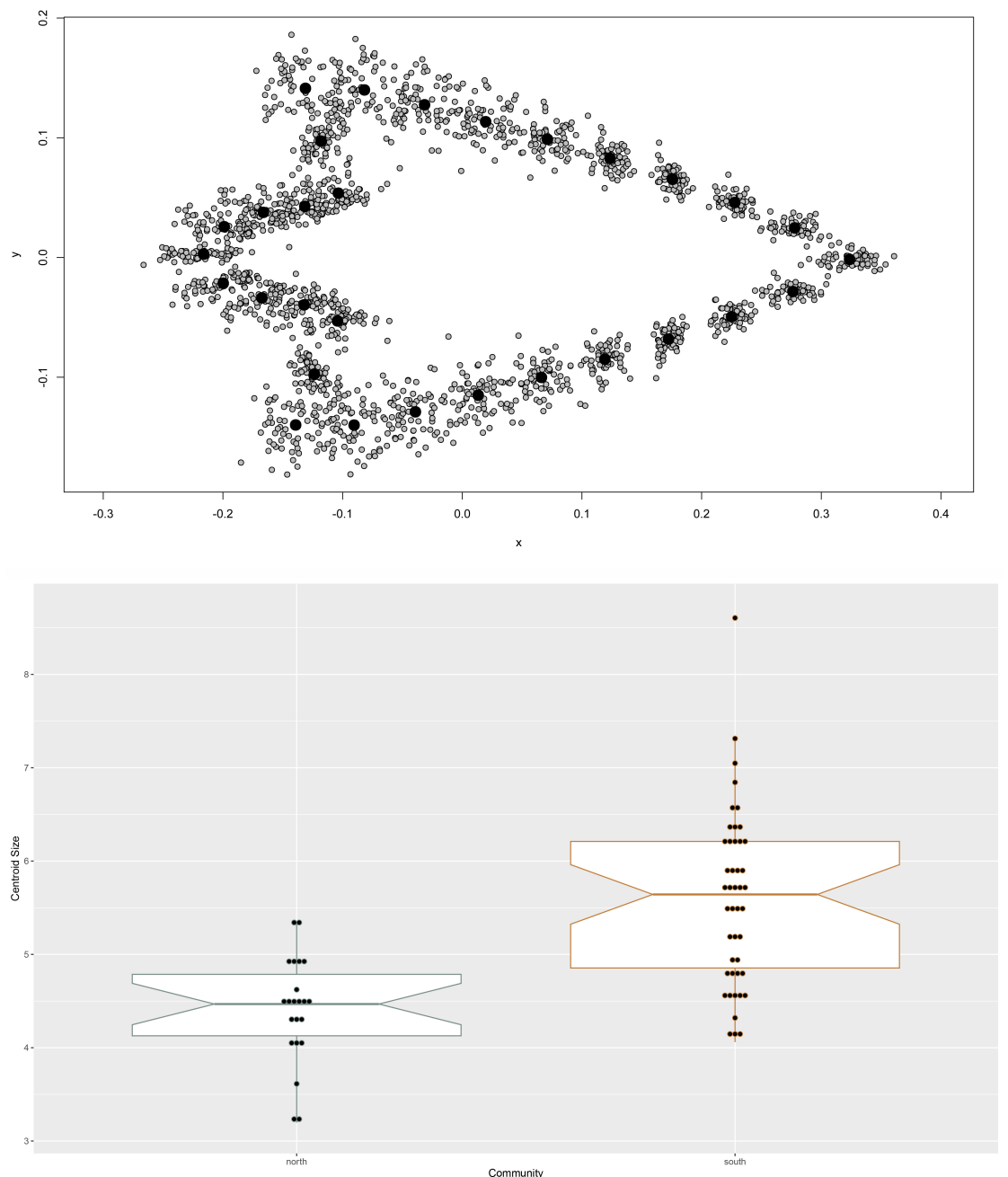

Fig. 3 Results of generalized Procrustes analysis, illustrating mean shape (black) and all specimens in the sample (gray), as well as the difference in centroid size for Perdiz arrow points from the two behavioral regions. Additional information related to the GPA, including all data and code needed to reproduce these results, can be found in the supplemental materials at https://seldenlab.github.io/perdiz3/.

the south), suggesting that between-region differences in Perdiz arrow point size may be more visually apparent than differences in shape. A comparison of mean consensus configurations was used to illustrate shape differences from the northern and southern behavioral regions. Diacritical morphology is characterized by a comparatively smaller blade and larger stem in the north, and by a comparatively larger blade and smaller stem in the south. Further, the angle between the shoulder and base is more acute, with a base that is gen- 

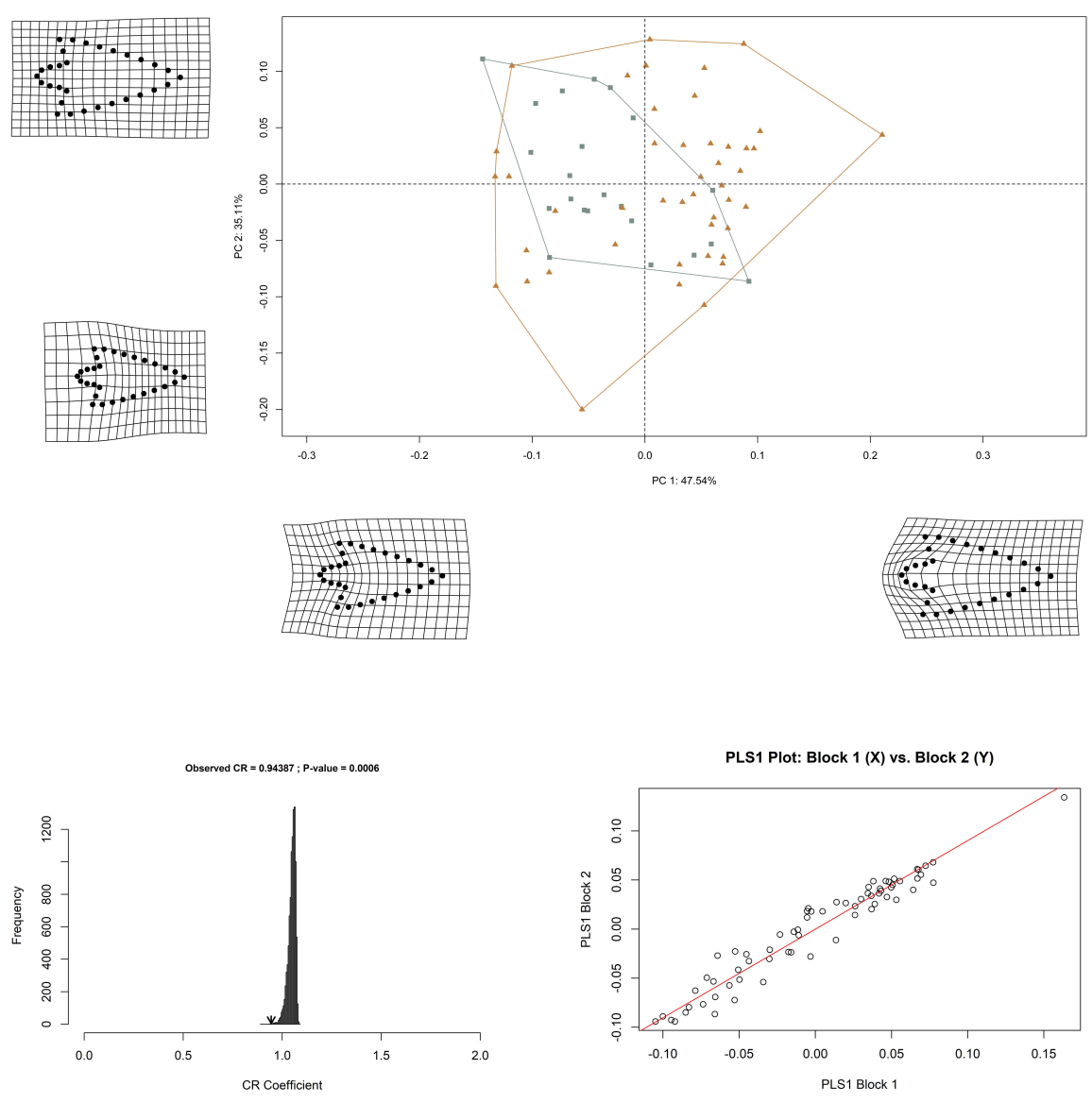

Fig. 4 Principal components analysis plot (PC1/PC2) for Perdiz arrow points by behavioral region/community (top; gray squares, north; orange triangles, south), and results of modularity (bottom left) and blade/base morphological integration (bottom right) analyses. Additional information related to the PCA, including the full listing of results and all data and code needed to reproduce these results, can be found in the supplemental materials at https://seldenlab.github.io/perdiz3/.

erally shorter and narrower in the southern behavioral region (supplementary materials).

The analysis of modularity, which compares within-module covariation of landmarks against between-module covariation was significant (see Figure 4 and supplementary materials) 3,6, demonstrating that Perdiz arrow point blades and bases are, in fact, modular. The test for morphological integration was also significant (see Figure 4 and supplementary materials), indicating that the blades and bases of Perdiz arrow points are integrated. These results demonstrate that blade and base shapes for Perdiz arrow points are 
predictable; a finding that would have utility in subsequent studies of Perdiz arrow point morphology that incorporate fragmentary specimens.

\section{Discussion}

The shape boundary empirically delineates two discrete behavioral regions in the ancestral Caddo area. That Perdiz arrow points recovered from Caddo burials north and south of the shape boundary were found to differ significantly, expands the scope of the behavioral regions to include three classes of material culture (Caddo bottles, bifaces, and - now - arrow points) 62, 63, 64, 66, 68, 69,61. Thus, for material culture included in burial contexts north and south of the shape boundary, the Caddo were selecting for significant morphological differences in bottles, bifaces, and arrow points (Figure $5 \mathrm{a}-\mathrm{d}$ ). Results clearly illustrate that morphological differences among Perdiz arrow points found in the northern and southern behavioral regions (Figure 5d) are predictable (supplementary materials), and can be disaggregated using a standard suite of linear metrics regularly collected in the course of cultural resource management endeavors.

The geometric morphometric analysis demonstrated significant morphological differences for Perdiz arrow points recovered north and south of the shape boundary, where the most pronounced difference was found to occur in basal morphology (see Figure 5d). This finding provides evidence in support of the argument that Perdiz arrow point morphology is labile [67. The character of those morphological differences found to occur in Perdiz arrow points (basal morphology and size) is potentially suggestive of differential approaches to hafting.

Blades and bases of Perdiz arrow points were found to be both modular and morphologically integrated. This indicates that each module functions independently, and that basal shape is a predictor of blade shape, and viceversa. Further work is warranted to assess whether Perdiz arrow points from groups within the boundaries of the northern and southern behavioral regions may express unique morphologies, aiding in further delimiting local boundaries associated with constituent Caddo groups.

\subsection{Morphologically-distinct behavioral regions}

In considering the role/s of material culture as aspects of social identity, it is important not to lose sight of the fact that people and their possessions are active agents in the production and maintenance of social identity/ies. All three categories of material culture (bottles, bifaces, and arrow points) contribute to local and regional communities of identity and communities of practice 27]. Generally, this concept may be more easily applied to bottles since those were manufactured and used by individuals sharing collective Caddo identities. Bifaces and arrow points potentially represent multiple identities - those being 


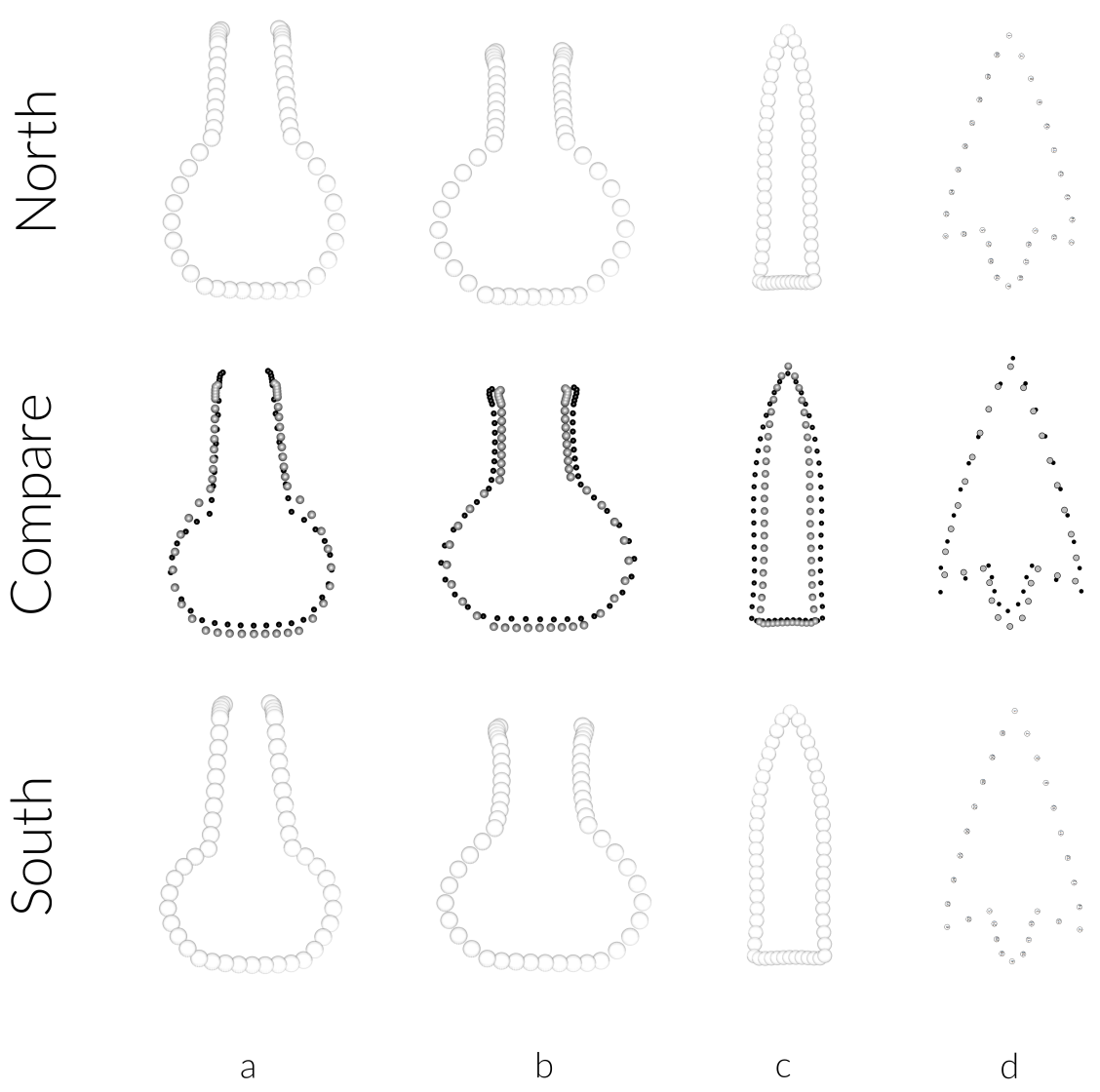

Fig. 5 Mean shapes and comparisons for a, Formative/Early and b, Late/Historic bottles; c, Formative/Early Gahagan bifaces; and d, Middle/Late Perdiz arrow points from Caddo burial contexts in the northern and southern behavioral regions. In the comparisons of mean shape, the northern population appears in gray, and the southern population appears in black.

the Caddo, as users; and non-Caddo, as producers - at least with regard to chipped stone tools incorporated in mortuary contexts. This concept lends defensible credence to the notion of morphologically-distinct behavioral regions among the Caddo, while integrating the possibility of understanding interactions between Caddo and non-Caddo groups, to include the movement of material culture between Caddo behavioral regions.

Three categories of Caddo material culture have been demonstrated to differ north and south of the shape boundary, indicating a haecceity of regional perspectives related to production (bottles), and aesthetic choice/cultural interaction (bifaces and arrow points). These differing perspectives incorporate normative group decisions that include shape, size, form, and decorative expression, which likely represent the culmination of generational perspectives 
74. Simply stated, such perspectives are representative of tradition. Eckert and colleagues 27] indicate that provenance, the origin or source of an item, is a significant component of understanding the interrelatedness of communities of identity and communities of practice. A second shape boundary demonstrates that Gahagan bifaces differ significantly between the ancestral Caddo region and central Texas, where they are currently thought to have been manufactured. This suggests that those communities of practice that articulate with the production of chipped stone artifacts recovered from Caddo internments, may not have been Caddo.

It is also entirely possible that there are no communities of practice for chipped stone artifacts recovered from Caddo mortuary contexts. However, there do appear to have been communities of practice associated with Perdiz arrow points recovered from non-mortuary contexts in the ancestral Caddo area, which may more readily reflect retouch or resharpening approaches used by Caddo knappers 67, 71,61. Similar interpretations can be applied to the Gahagan bifaces, as few have been reported outside of Caddo mortuary contexts. It may be more fitting to perceive of Perdiz arrow points and Gahagan bifaces as indicative of communities of identity rather than communities of practice, due to the contextual discrepancy evinced through mortuary and non-mortuary settings. The provenance of bifaces from Caddo mortuary contexts can most assuredly be considered non-local, or produced outside of the ancestral Caddo region, based on multiple factors that include raw material, workmanship, morphology, and context.

\section{Conclusion}

This study demonstrated that linear metrics and shape variables collected for Perdiz arrow points support the shape boundary posited in recent social network and geometric morphometric analyses, and determined that those same metrics can be used to predict regional membership. Morphological features that discriminate between Perdiz arrow points recovered from each behavioral region were identified using geometric morphometrics, with substantive differences found to occur in size and basal morphology. Blade and base shape were found to be both modular and morphologically integrated, suggesting that blade and base shapes are predictable. While evidence from one categoryCaddo bottles - supports discussions of Caddo production, the other twobifaces and arrow points - may articulate with production activities outside of the region by non-Caddo makers. Such production activity is more likely to be localized than exchange systems, thus assumed to leave a clearer signature 24.

\section{Acknowledgments}

We extend our gratitude to the Caddo Nation of Oklahoma, the Caddo Nation Tribal Council, Tribal Chairman, and Tribal Historic Preservation Office for 
their continued guidance and support of our work, as well as access to NAGPRA and previously repatriated collections. Thanks also to the Anthropology and Archaeology Laboratory at Stephen F. Austin State University for the requisite permissions and access to the NAGPRA objects from the Washington Square Mound site and Turner collections, and to Tom A. Middlebrook for brokering access to the Perdiz arrow points from burials at the Morse Mound site. We wish to thank Michael J. Shott and Casey Wayne Riggs for their useful comments and constructive criticisms on a presubmission draft, and extend our gratitude to Emma Sherratt, Kersten Bergstrom, Lauren Butaric, Julien Claude, Dean C. Adams, and Michael L. Collyer for their constructive criticisms and suggestions throughout the development of this research program. Additional comments from the editor and three anonymous reviewers aided in further refining the manuscript.

\section{Funding}

Components of the analytical workflow were developed and funded by a Preservation Technology and Training grant (P14AP00138) to RZS from the National Center for Preservation Technology and Training, as well as grants to RZS from the Caddo Nation of Oklahoma, National Forests and Grasslands in Texas (15-PA-11081300-033) and the United States Forest Service (20-PA11081300-074). Additional funding and logistical support was provided by the Heritage Research Center at Stephen F. Austin State University.

\section{Data Management}

The data and analysis code associated with this project can be accessed through the GitHub repository (https://github.com/seldenlab/perdiz3) or the supplementary materials (https://seldenlab.github.io/perdiz3/); which are digitally curated on the Open Science Framework (DOI: 10.17605/OSF.IO/VZHJR). Images of all Perdiz arrow points used in this study were made available in an open access comparative collection (https://scholarworks.sfasu.edu/ita-perdiz/), with permission from the Caddo Nation of Oklahoma. These supplementary materials include all analysis data and code used in the study, providing a means for others to reproduce (exactly) those results discussed and expounded upon in this article. The replicable nature of this undertaking provides others with the means to critically assess and evaluate the various analytical components of this study, which is a necessary requirement for the production of reliable knowledge [33, 53, 30].

Reproducibility projects in psychology and cancer biology are impacting current research practices across all domains. Examples of reproducible research are becoming more abundant in archaeology [46, 34, 68, 67,61, and the next generation of archaeologists are learning those tools and methods needed 
to reproduce and/or replicate research results [47. Reproducible and replicable research work flows are often employed at the highest levels of humanitiesbased inquiries to mitigate concern or doubt regarding proper execution, and is of particular import should the results have - explicitly or implicitly — a major impact on scientific progress [52].

\section{References}

1. Adams, D.C., Collyer, M.L.: Permutation Tests for Phylogenetic Comparative Analyses of High-Dimensional Shape Data: What you Shuffle Matters. Evolution 69(3), 823-9 (2015). DOI 10.1111/evo.12596. URL http://www.ncbi.nlm.nih.gov/pubmed/ 25641367https://onlinelibrary.wiley.com/doi/abs/10.1111/evo.12596

2. Adams, D.C., Collyer, M.L.: On the Comparison of the Strength of Morphological Integration across Morphometric Datasets. Evolution 70(11), 2623-2631 (2016). DOI 10.1111/evo.13045. URL https://www.ncbi.nlm.nih.gov/pubmed/27592864https:// onlinelibrary.wiley.com/doi/abs/10.1111/evo.13045

3. Adams, D.C., Collyer, M.L.: Comparing the strength of modular signal, and evaluating alternative modular hypotheses, using covariance ratio effect sizes with morphometric data. Evolution 73(12), 2352-2367 (2019). DOI 10.1111/evo.13867. URL https://www . ncbi.nlm.nih.gov/pubmed/31657008

4. Adams, D.C., Collyer, M.L., Kaliontzopoulou, A., Sherratt, E.: Package 'geomorph': Geometric Morphometric Analyses of 2D/3D Landmark Data. R package version 3.2.1 (March 1, 2020) (2018). URL http://geomorphr.github.io/geomorph/

5. Adams, D.C., Otarola-Castillo, E.: geomorph: An R Package for the Collection and Analysis of Geometric Morphometric Shape Data. Methods in Ecology and Evolution 4(4), 393-399 (2013). DOI 10.1111/2041-210x.12035. URL https://besjournals.onlinelibrary.wiley.com/doi/full/10.1111/2041210X.12035https://besjournals.onlinelibrary.wiley.com/doi/pdfdirect/10. 1111/2041-210X.12035?download=true

6. Adams, D.C., Peres-Neto, P.: Evaluating modularity in morphometric data: challenges with the RV coefficient and a new test measure. Methods in Ecology and Evolution 7(5), 565-572 (2016). DOI 10.1111/2041-210x.12511. URL https://besjournals.onlinelibrary.wiley.com/doi/full/10.1111/2041210X.12511https://besjournals.onlinelibrary.wiley.com/doi/pdfdirect/10. 1111/2041-210X.12511?download=true

7. Anderson, M.J., Ter Braak, C.J.F.: Permutation Tests for Multi-Factoral Analysis of Variance. Journal of Statistical Computation and Simulation 73(2), 85-113 (2003). DOI 10.1080 $=0094965021000015558$

8. Arnn III, J.W.: Chronology, Technology, and Subsistence: Is That All There Is? Council of Texas Archeologists Newsletter 29(2), 17-28 (2005)

9. Arnn III, J.W.: Transformation and persistence of indigenous cultural identity during the early colonial and late prehistoric periods in texas. Thesis (2007)

10. Arnn III, J.W.: Defining Hunter-Gatherer Sociocultural Identity and Interaction at a Regional Scale, pp. 44-75. Texas A\&M University Press, College Station (2012)

11. Arnn III, J.W.: Land of the Tejas: Native American Identity and Interaction in Texas, A.D. 1300 - 1700. The University of Texas Press, Austin (2012)

12. Baken, E.K., Collyer, M.L., Kaliontzopoulou, A., Adams, D.C.: geomorph v4.0 and gmShiny: Enhanced analytics and a new graphical interface for a comprehensive morphometric experience. Methods in Ecology and Evolution (2021). DOI 10.1111/2041210x.13723

13. Banks, L.D.: From Mountain Peaks to Alligator Stomachs: A Review of Lithic Sources in the Trans-Mississippi South, The Southern Plains. Memoir No. 4. Oklahoma Anthropological Society, Norman (1990)

14. Bhatt, M.S., Patalia, T.P.: Indian monuments classification using support vector machine. International Journal of Electrical and Computer Engineering (IJECE) $7(4)$ (2017). DOI 10.11591/ijece.v7i4.pp1952-1963 
15. Birkhoff, G.D.: Aesthetic Measure. Harvard University Press, Cambridge (1933)

16. Black, S.L.: The clemente and herminia hinojosa site, 41jw8: A toyah horizon campsite in southern texas. Report, No. 18, Center for Archaeological Research, The University of Texas at San Antonio (1986). DOI https://doi.org/10.21112/ita.1986.1.36. URL https://scholarworks.sfasu.edu/ita/vol1986/iss1/36/

17. Blondel, V.D., Guillaume, J.L., Lambiotte, R., Lefebvre, E.: Fast Unfolding of Communities in Large Networks. Journal of Statistical Mechanics: Theory and Experiment 2008(10), P10008 (2008). DOI 10.1088/1742-5468/2008/ 10/p10008. URL <GotoISI>://WOS:000260529900010https://iopscience.iop.org/ article/10.1088/1742-5468/2008/10/P10008

18. Bookstein, F.L., Gunz, P., Mitterocker, P., Prossinger, H., Schaefer, K., Seidler, H.: Cranial Integration in Homo: Singular Warps Analysis of the Midsagittal Plane in Ontogeny and Evolution. Journal of Human Evolution 44(2), 167-187 (2003). DOI 10.1016/S00472484(02)00201-4. URL https://www.ncbi.nlm.nih.gov/pubmed/12662941https:// WwW.sciencedirect.com/science/article/abs/pii/S0047248402002014?via\%3Dihub

19. Buitinck, L., Louppe, G., Blondel, M., Pedregosa, F., Mueller, A., Grisel, O., Niculae, V., Prettenhofer, P., Gramfort, A., Grobler, J., Layton, R., VanderPlas, J., Joly, A., Holt, B., Varoquaux, G.: API design for machine learning software: experiences from the scikit-learn project. In: ECML PKDD Workshop: Languages for Data Mining and Machine Learning, pp. 108-122 (2013)

20. Cassaway, L.: Indian-Pioneer History Project for Oklahoma: Sadie Bedoka (1937)

21. Collins, M.B.: Forty Years of Archaeology in Central Texas. Bulletin of the Texas Archeological Society 66, 361-400 (1995)

22. Collyer, M.L., Adams, D.C.: RRPP: An R Package for Fitting Linear Models to HighDimensional Data using Residual Randomization. Methods in Ecology and Evolution 9(7), 1772-1779 (2018). DOI https://doi.org/10.1111/2041-210X.13029. URL https: //bes journals.onlinelibrary.wiley.com/doi/pdf/10.1111/2041-210X.13029https: //besjournals.onlinelibrary.wiley.com/doi/full/10.1111/2041-210X.13029

23. Collyer, M.L., Sekora, D.J., Adams, D.C.: A method for analysis of phenotypic change for phenotypes described by high-dimensional data. Heredity (Edinb) 115(4), 357-65 (2015). DOI 10.1038/hdy.2014.75. URL http://www.ncbi.nlm.nih.gov/pubmed/25204302https://www.ncbi.nlm.nih.gov/ pmc/articles/PMC4815463/pdf/hdy201475a.pdf

24. Costin, C.L.: Craft Specialization: Issues in Defining, Documenting, and Explaining the Organization of Production, pp. 1-56. University of Arizona Press, Tucson (1991)

25. Dering, P.: Late Prehistoric Subsistence Economy on the Edwards Plateau. Plains Anthropologist 53(205), 59-77 (2008). DOI 10.1179/pan.2008.005

26. Dockall, J.E., Fields, R.C., Kibler, K.W., Broehm, C.J., Budd, J., Gadus, E.F., Gardner, K.M.: Testing and Data Recovery Excavations at the Jayroe Site (41HM51), Hamilton County, Texas (Waco District, CSJ No. 0909-29-030 (Part I)). Tech. rep., Reports of Investigations No. 187. Prewitt and Associates, Inc., Austin Texas. Archeological Studies Program, Report No. 184. Texas Department of Transportation, Environmental Affairs Division, Archeological Studies Branch, Austin Texas (2020)

27. Eckert, S.L., Schleher, K.L., James, W.D.: Communities of Identity, Communities of Practice: Understanding Santa Fe Black-on-White Pottery in the Espanola Basin of New Mexico. Journal of Archaeological Science 63, 1-12 (2015). DOI 10. 1016/j.jas.2015.07.001. URL https://www.sciencedirect.com/science/article/pii/ S030544031500223X?via\%3Dihub

28. Elliot, T., Morse, R., Smythe, D., Norris, A.: Evaluating machine learning techniques for archaeological lithic sourcing: A case study of flint in Britain. Sci Rep 11(1), 10197 (2021). DOI 10.1038/s41598-021-87834-3. URL https://www.ncbi.nlm.nih. gov/pubmed/33986304

29. Febriawan, H.K., Moefti, O., Haryanto, D., Wiguna, T.: Detection and characterization of an archaeological wreck site in Sunda Strait, Indonesia. Forum geografic XIX(1), 60-71 (2020). DOI 10.5775/fg.2020.054.i

30. Gandrud, C.: Reproducible Research with R and RStudio. The R Series. CRC Press, London (2014)

31. Goodall, C.: Procrustes Methods in the Statistical Analysis of Shape. Journal of the Royal Statistical Society. Series B (Methodological) 53(2), 285-339 (1991) 
32. Gower, J.C.: Generalized Procrustes Analysis. Psychometrika 40(1), 33-51 (1975). DOI https://doi.org/10.1007/BF02291478. URL https://link. springer.com/article/10. $1007 \% 2 \mathrm{FBF} 02291478$

33. Gray, C.T., Marwick, B.: Truth, Proof, and Reproducibility: There's No Counter-Attack for the Codeless, book section Chapter 8, pp. 111-129. Communications in Computer and Information Science (2019). DOI 10.1007/978-981-15-1960-4_8

34. Ivanovaitè, L., Serwatka, K., Hoggard, C.S., Sauer, F., Riede, F.: All these fantastic cultures? research history and regionalization in the late palaeolithic tanged point cultures of eastern europe. European Journal of Archaeology 23(2), 162-185 (2020). DOI $10.1017 /$ eaa. 2019.59

35. Johnson, L.: The Life and Times of Toyah-Culture Folk: The Buckhollow Encampment Site 41KM16, Kimble County, Texas. Report, Texas Department of Transportation and Office of the State Archeologist Report 38. Austin, Texas (1994)

36. Jolliffe, I.T.: Principal Component Analysis. Springer, New York (2002)

37. Kadhim, I., Abed, F.: The Potential of LiDAR and UAV-Photogrammetric Data Analysis to Interpret Archaeological Sites: A Case Study of Chun Castle in SouthWest England. ISPRS International Journal of Geo-Information 10(1) (2021). DOI 10.3390/ijgi10010041

38. Kelley, J.C.: The cultural affiliations and chronological position of the Clear Fork focus. American Antiquity 13(2), 97-109 (1947)

39. Kelley, J.C.: The Lehmann Rock Shelter: A Stratified Site of the Toyah, Uvalde, and Round Rock Foci. Bulletin of the Texas Archeological and Paleontological Society 18, 115-128 (1947)

40. Kendall, D.G.: The Statistics of Shape, pp. 75-80. Wiley, New York (1981)

41. Kendall, D.G.: Shape manifolds, procrustean metrics, and complex projective spaces. Bulletin of the London Mathematical Society 16(2), 81-121 (1984). DOI 10.1112/blms/16.2.81. URL http://onlinelibrary.wiley.com/doi/10.1112/blms/16. 2.81/abstracthttps://londmathsoc.onlinelibrary.wiley.com/doi/abs/10.1112/ $\mathrm{blms} / 16.2 .81$

42. Klingenberg, C.P.: Visualizations in Geometric Morphometrics: How to Read and How to Make Graphs Showing Shape Changes. Hystrix 24, 15-24 (2013)

43. Knappett, C.: An Archaeology of Interaction: Network Perspectives on Material Culture \& Society. Oxford University Press, Oxford (2011)

44. Krieger, A.D.: Culture Complexes and Chronology in Northern Texas, with Extensions of Puebloan Datings to the Mississippi Valley, vol. Publication No. 4640. The University of Texas, Austin (1946)

45. Lambiotte, R., Delvenne, J.C., Barahona, M.: Random Walks, Markov Processes and the Multiscale Modular Organization of Complex Networks. IEEE Transactions on Network Science and Engineering 1(2), 76-90 (2014). DOI 10.1109/tnse.2015.2391998. URL https://ieeexplore .ieee.org/document/7010026/

46. Marwick, B.: Computational reproducibility in archaeological research: Basic principles and a case study of their implementation. Journal of Archaeological Method and Theory 24(2), 424-450 (2016). DOI 10.1007/s10816-015-9272-9

47. Marwick, B., Wang, L.Y., Robinson, R., Loiselle, H.: How to use replication assignments for teaching integrity in empirical archaeology. Advances in Archaeological Practice 8(1), 78-86 (2019). DOI 10.1017/aap.2019.38

48. Mills, B.J., Peeples, M.A., Haas Jr., W.R., Borck, L., Clark, J.J., Roberts Jr., J.M.: Multiscalar Perspectives on Social Networks in the Late Prehispanic Southwest. American Antiquity 80(1), 3-24 (2015). DOI 10.7183/0002-7316.79.4.3. URL https://www.cambridge.org/core/journals/american-antiquity/article/ multiscalar-perspectives-on-social-networks-in-the-late-prehispanicsouthwest/B40CF133F9E61102185B25AD4DF0FE30

49. Monna, F., Magail, J., Rolland, T., Navarro, N., Wilczek, J., Gantulga, J.O., Esin, Y., Granjon, L., Allard, A.C., Chateau-Smith, C.: Machine learning for rapid mapping of archaeological structures made of dry stones - example of burial monuments from the khirgisuur culture, mongolia -. Journal of Cultural Heritage 43, 118-128 (2020). DOI 10.1016/j.culher.2020.01.002 
50. Olsen, A.M., Westneat, M.W.: Stereomorph: An r package for the collection of 3d landmarks and curves using a stereo camera set-up. Methods in Ecology and Evolution 6(3), 351-356 (2015). DOI 10.1111/2041-210x.12326

51. Pedregosa, F., Varoquaux, G., Gramfort, A., Michel, V., Thirion, B., Grisel, O., Blondel, M., Prettenhofer, P., Weiss, R., Dubourg, V., Vanderplas, J., Passos, A., Cournapeau, D., Brucher, M., Perrot, M., Duchesnay, E.: Scikit-learn: Machine Learning in Python. Journal of Machine Learning Research 12, 2825-2830 (2011)

52. Peels, R., Bouter, L.: Humanities need a replication drive too. Nature 558(7710), 372 (2018). DOI 10.1038/d41586-018-05454-w. URL https://www.ncbi.nlm.nih.gov/ pubmed/29921855

53. Peng, R.D.: Reproducible research in computational science. Science 334(6060), 1226-7 (2011). DOI 10.1126/science.1213847. URL https://www.ncbi.nlm.nih.gov/pubmed/ 22144613

54. Prewitt, E.R.: Culture Chronology in Texas. Bulletin of the Texas Archeological Society 52, 65-89 (1981)

55. Prewitt, E.R.: From Circleville to Toyah: Comments on Central Texas Chronology. Bulletin of the Texas Archeological Society 54, 201-238 (1985)

56. Revell, L.J.: Size-correction and principal components for interspecific comparative studies. Evolution 63(12), 3258-68 (2009). DOI 10.1111/j.1558-5646.2009.00804.x. URL https://www.ncbi.nlm.nih.gov/pubmed/19663993

57. Ricklis, R.A.: Toyah Components: Evidence for Occupation in the Project Area during the Latter Part of the Late Prehistoric Period, pp. 207-316. Studies in Archeology 19. Vol. 1, Texas Archeological Research Laboratory, University of Texas, Austin, Texas (1994)

58. Ricklis, R.A.: The Spread of a Late Prehistoric Bison Hunting Complex: Evidence from the South-Central Coastal Prairie of Texas. Plains Anthropologist 37(140), 261-273 (2017). DOI 10.1080/2052546.1992.11909654

59. Rohlf, F.J.: Shape Statistics: Procrustes Superimpositions and Tangent Spaces. Journal of Classification 16(2), 197-223 (1999). DOI 10.1007/s003579900054. URL https: //link.springer.com/article/10.1007\%2Fs003579900054

60. Rohlf, F.J., Slice, D.E.: Extensions of the Procrustes Method for the Optimal Superimposition of Landmarks. Systematic Zoology 39(1), 40-59 (1990). DOI 10. $2307 / 2992207$. URL https://academic.oup.com/sysbio/article-abstract/39/1/40/ 1629843?redirectedFrom=fulltext

61. Selden, R.Z.: Morphologically Similar, but Regionally Distinct: Perdiz Arrow Points from Caddo Burial Contexts in the American Southeast. Lithic Technology (in press) (2022). DOI 10.1080/01977261.2022.2095492. URL https://doi.org/10.1080/ 01977261.2022 .2095492

62. Selden Jr., R.Z.: A Preliminary Study of Smithport Plain Bottle Morphology in the Southern Caddo Area. Bulletin of the Texas Archeological Society 89, 63-89 (2018). URL https : //scholarworks . sfasu .edu/crhr/283/

63. Selden Jr., R.Z.: Ceramic Morphological Organisation in the Southern Caddo Area: Quiddity of Shape for Hickory Engraved Bottles. Journal of Archaeological Science: Reports 21, 884-896 (2018). DOI 10.1016/j.jasrep.2018.08.045

64. Selden Jr., R.Z.: Ceramic Morphological Organisation in the Southern Caddo Area: The Clarence H. Webb Collections. Journal of Cultural Heritage 35, 41-55 (2019). DOI 10. 1016/j.culher.2018.07.002. URL https://www.sciencedirect.com/science/article/ abs/pii/S1296207418301912?via\%3Dihub

65. Selden Jr., R.Z.: An Exploratory Network Analysis of the Historic Caddo Period in Northeast Texas. In: D.P. McKinnon, T.K. Perttula, J.S. Girard (eds.) Ancestral Caddo Ceramic Traditions, pp. 240-257. LSU Press, Baton Rouge (2021)

66. Selden Jr., R.Z.: Louisiana Limitrophe: An Iterative Morphological Exegesis of Caddo Bottle and Biface Production. In: D.P. McKinnon, J.S. Girard, T.K. Perttula (eds.) Ancestral Caddo Ceramic Traditions, pp. 258-276. LSU Press, Baton Rouge (2021)

67. Selden Jr, R.Z., Dockall, J.E., Bousman, C.B., Perttula, T.K.: Shape as a function of time + raw material + burial context? An exploratory analysis of Perdiz arrow points from the ancestral Caddo area of the American Southeast. Journal of Archaeological Science: Reports 37 (2021). DOI 10.1016/j.jasrep.2021.102916 
68. Selden Jr., R.Z., Dockall, J.E., Dubied, M.: A quantitative assessment of intraspecific morphological variation in Gahagan bifaces from the southern Caddo area and central Texas. Southeastern Archaeology 39(2), 125-145 (2020). DOI 10.1080/0734578x.2020. 1744416

69. Selden Jr., R.Z., Dockall, J.E., Shafer, H.J.: Lithic Morphological Organisation: Gahagan Bifaces from the Southern Caddo Area. Digital Applications in Archaeology and Cultural Heritage 10, e00080 (2018). DOI 10.1016/j.daach.2018.e00080

70. Selden Jr., R.Z., Perttula, T.K., O'Brien, M.J.: Advances in Documentation, Digital Curation, Virtual Exhibition, and a Test of 3D Geometric Morphometrics: A Case Study of the Vanderpool Vessels from the Ancestral Caddo Territory. Advances in Archaeological Practice 2(2), 1-15 (2014). DOI 10.7183/2326-3768.2.2.64

71. Shafer, H.J.: Lithic Reduction Strategies at the George C. Davis Site. Louisiana Archaeology 1, 66-74 (1974). URL https://docs.wixstatic.com/ugd/fefb33_ 71a3f0c39e5d47a2b55af09847e6d821.pdf

72. Sherratt, E., Gower, D.J., Klingenberg, C.P., Wilkinson, M.: Evolution of Cranial Shape in Caecilians (Amphibia: Gymnophiona). Evolutionary Biology 41, 528-545 (2014). DOI https://doi.org/10.1007/s11692-014-9287-2. URL https://link.springer.com/ article/10.1007\%2Fs11692-014-9287-2

73. Slice, D.E.: Landmark Coordinates Aligned by Procrustes Analysis Do Not Lie in Kendall's Shape Space. Systematic Biology 50(1), 141-149 (2001). DOI 10.1080/ 10635150119110

74. Stark, M.T.: Glaze Ware Technology, the Social Lives of Pots, and Communities of Practice in the Late Prehistoric Southwest, pp. 17-33. University of Arizona Press, Tucson (2006)

75. Suhm, D.A., Jelks, E.B.: Handbook of Texas Archeology: Type Descriptions. Special Publication No. 1. Texas Archeological Society and Bulletin No. 4, Texas Memorial Museum, Austin (1962)

76. Suhm, D.A., Krieger, A.D., Jelks, E.B.: An Introductory Handbook of Texas Archeology. Bulletin of the Texas Archeological Society 25, 1-562 (1954)

77. Team, R.C.D.: R: A Language and Environment for Statistical Computing. Electronic resource,. R Foundation for Statistical Computing, Vienna, Austria (2021). URL http: //www.R-project.org

78. Turner, E.S., Hester, T.R., McReynolds, R.L.: Stone Artifacts of Texas Indians: Completely Revised Third Edition. Taylor Trade Publishing, Lanham, Maryland (2011)

79. Zelditch, M.L., Swiderski, D.L., Sheets, H.D., Fink, W.L.: Geometric Morphometrics for Biologists : A Primer. Elsevier Science, Burlington (2004). URL http://ebookcentral. proquest. com/lib/tamucs/detail.action?docID $=298308$

80. Zhang, R.: The ancient ceramics identification methods based on non-linear support vector machines. In: Applied Mechanics and Materials, vol. 278, pp. 1201-1204. Trans Tech Publ (2013) 